\title{
The calculation of neutron flux using Monte Carlo method
}

\author{
Mehtap Günay ${ }^{*}$, Hilal Bardakçı \\ İnönü University, Science and Art Faculty, Physics Department, Malatya, Turkey
}

\begin{abstract}
In this study, a hybrid reactor system was designed by using $99-95 \% \mathrm{Li}_{20} \mathrm{Sn}_{80}+1-5 \% \mathrm{RG}-\mathrm{Pu}$, 99-95\% $\mathrm{Li}_{20} \mathrm{Sn}_{80}+1-5 \% \mathrm{RG}_{-} \mathrm{PuF}_{4}$, and $99-95 \% \mathrm{Li}_{20} \mathrm{Sn}_{80}+1-5 \% \mathrm{RG}_{-} \mathrm{PuO}_{2}$ fluids, ENDF/B-VII.0 evaluated nuclear data library and $9 \mathrm{Cr} 2 \mathrm{WVTa}$ structural material. The fluids were used in the liquid first wall, liquid second wall (blanket) and shield zones of a fusion-fission hybrid reactor system. The neutron flux was calculated according to the mixture components, radial, energy spectrum in the designed hybrid reactor system for the selected fluids, library and structural material. Three-dimensional nucleonic calculations were performed using the most recent version MCNPX-2.7.0 the Monte Carlo code.
\end{abstract}

\section{Introduction}

The waste management required as a result of fuel burning to generate energy from traditional nuclear reactors is one of the most important problems today. For this reason, hybrid reactor system has been developed where fusion and fission occur at the same time. Hybrid reactor is a system developed to obtain more energy and nuclear fuel, decrease the waste amounts in storage areas, recover transuranic elements in used fuels through reprocessing, and render fission products harmless [1-5].

Reactor-grade (RG) plutonium is found in spent nuclear fuel. Isotopic distribution of $\mathrm{RG}-\mathrm{Pu}$ has composition $1 \%{ }^{238} \mathrm{Pu}, 62 \%{ }^{239} \mathrm{Pu}, 24 \%{ }^{240} \mathrm{Pu}, 8 \%{ }^{241} \mathrm{Pu}$ and $5 \%{ }^{242} \mathrm{Pu}[6]$. In this study, $\mathrm{Li}_{20} \mathrm{Sn}_{80}$ molten salt was used, which has low melting temperatures and low vapor pressure, to acquire sufficient tritium breeding. Beryllium (Be) is used as a neutron multiplier [7]. In this study, a Be zone with a thickness of $3 \mathrm{~cm}$ was used between the liquid first-wall and the blanket. In this study, 9Cr2WVTa ferritic steel was chosen as a structural material because it has low activation, which can help to extend the lifetime of the reactor system. The main objective of this study is to investigate the neutron flux according to the mixture components, radial, energy spectrum in the designed hybrid reactor system for the selected fluids, library and structural material.

\section{Method}

\subsection{Numerical Calculations and Neutron Flux}

The radial structure of the hybrid reactor system is shown in Table 1. Calculation of all the parameters of the fission and fusion reactors, accelerator-driven systems, and other areas of nuclear technology depend on the cross-section data. The experimental data are limited for neutron-produced reactions in certain energy ranges. The data of the ENDF/B-VII libraries are very important for theoretical calculations [8-12]. This study was performed with neutron wall loadings of $10 \mathrm{MW} / \mathrm{m}^{2}$ and fusion power of $4000 \mathrm{MW}$.

Table 1. The radial build of the hybrid reactor system design

\begin{tabular}{|c|c|c|c|}
\hline \multicolumn{2}{|c|}{ Inboard side } & \multicolumn{2}{|c|}{ Outboard side } \\
\hline Zone & $\mathbf{r}(\mathbf{c m})$ & Zone & $\mathbf{r}(\mathbf{c m})$ \\
\hline SS316LN & 276 & Plasma & 667 \\
\hline Vacuum vessel $^{\mathrm{a}}$ & 278 & SOL & 695 \\
\hline SS316LN & 294 & $\begin{array}{l}\text { Liquid First } \\
\text { Wall }^{\mathrm{d}}\end{array}$ & 697 \\
\hline GAP & 296 & $\mathrm{Be}^{\mathrm{e}}$ & 700 \\
\hline Shield $^{\mathrm{b}}$ & 301 & Blanket $^{\mathrm{d}}$ & 750 \\
\hline Ferritic Steel $^{\mathrm{c}}$ & 350 & Ferritic Steel $^{\mathrm{c}}$ & 754 \\
\hline Blanket $^{\mathrm{d}}$ & 354 & Shield $^{\mathrm{b}}$ & 804 \\
\hline $\mathrm{Be}^{\mathrm{e}}$ & 404 & GAP & 838 \\
\hline $\begin{array}{l}\text { Liquid First } \\
\text { Wall }^{\mathrm{d}}\end{array}$ & 407 & SS316LN & 840 \\
\hline SOL & 409 & Vacuum vessel $^{\mathrm{a}}$ & 866 \\
\hline Plasma & 437 & SS316LN & 868 \\
\hline $\begin{array}{ll}\text { a } & 80 \% \mathrm{SS} 316 \mathrm{LI} \\
\text { b } & 60 \% 9 \mathrm{Cr} 2 \mathrm{WV} \\
& 99-95 \% \mathrm{Li}_{20} \mathrm{~S} \\
& 99-95 \% \mathrm{Li}_{20} \mathrm{~S} \\
\text { c } & 100 \% 9 \mathrm{Cr} 2 \mathrm{~W} \\
\text { d } & 99-95 \% \mathrm{Li}_{20} \mathrm{~S} \\
& 99-95 \% \mathrm{Li}_{20} \mathrm{~S} \\
& 99-95 \% \mathrm{Li}_{20} \mathrm{~S} \\
\text { e } & 100 \% \mathrm{Be}\end{array}$ & $\begin{array}{l}0 \% \mathrm{H}_{2} \mathrm{O} \\
40 \%(9 \mathrm{C} \\
1-5 \% \mathrm{RC} \\
1-5 \% \mathrm{RC} \\
1-5 \% \mathrm{RC} \\
1-5 \% \mathrm{RC} \\
1-5 \% \mathrm{RC}\end{array}$ & $\begin{array}{l}\% \mathrm{Li}_{20} \mathrm{Sn}_{80}-1-5 \% \\
\mathrm{~F}_{4} \\
\left.\mathrm{O}_{2}\right) \\
\mathrm{F}_{4} \\
\mathrm{O}_{2}\end{array}$ & $\mathrm{Pu}$ \\
\hline
\end{tabular}

It is important for neutronic calculations to know the flux distribution of the neutrons in a nuclear fission reactor, fusion reactor, and hybrid reactor. The neutron flux is defined as the total path of thermal neutrons in a unit volume around point $r$ in a second. The neutron flux expresses a scalar value of dimensions $\mathrm{m}^{-2} \mathrm{~s}^{-1}$. In the nuclear reactors, fast neutrons are nearly exclusively produced in the fission reactions. In the nuclear reactors, the fast neutrons gradually slow due to collisions with the atoms of the moderator and the various nuclear processes taking place in the reactor [13]. As these

\footnotetext{
Corresponding author: mehtap.gunay@inonu.edu.tr
} 
formations are the functions of neutron energy, the neutron flux distribution should also be expressed as a function of neutron energy. The Boltzmann equation is a common way to calculate neutron flux in a reactor, which is given in below:

$$
\frac{1}{v} \frac{\partial}{\partial t} \phi(r, \Omega, E, t)+\Omega \cdot \nabla \phi(r, \Omega, E, t)+\sum_{t}(r, E, t) \phi(r, \Omega, E, t)=q(r, \Omega, E, t)(1)
$$

$\frac{1}{v} \frac{\partial}{\partial t} \phi(r, \Omega, E, t)=$ Change of neutron flux in unit time,

$\Omega . \nabla \phi(r, \Omega, E, t)=$ Neutron loss because of convection,

$\sum_{t}(r, E, t) \phi(r, \Omega, E, t)=$ Neutron loss because of nuclear reactions.

Terms in equation (1) for $q(r, \Omega, E, t)$ can be defined as follow:

$q(r, \Omega, E, t)=\int_{0}^{\infty} d E^{\prime} \int_{4 \pi} d \Omega \sum\left(r, E^{\prime} \rightarrow E, \Omega^{\prime} \rightarrow \Omega\right) \phi\left(r, \Omega^{\prime}, E^{\prime}, t\right)+S(r, \Omega, E, t)(2)$ $\int_{0}^{\infty} d E^{\prime} \int_{4 \pi} d \Omega \sum\left(r, E^{\prime} \rightarrow E, \Omega^{\prime} \rightarrow \Omega\right) \phi\left(r, \Omega^{\prime}, E^{\prime}, t\right)=$ Contribution of neutrons on neutron flux due to scattering,

$S(r, \Omega, E, t)=$ Contribution of neutron source independent on the neutron flux.

The transport equation is currently handled by the Monte Carlo method. The Monte Carlo method provides an instrument to solve the equations by simulating the neutron activities. In this study, neutron transport calculations of the neutron flux distributions were investigated using MCNPX-2.7.0 to solve the Boltzmann transport equation (1), (2) with Monte Carlo code.

\section{Numerical Results}

In this study, hybrid reactor system has designed by using 99-95\% $\mathrm{Li}_{20} \mathrm{Sn}_{80}+1-5 \% \mathrm{RG}-\mathrm{Pu}, 99-95 \% \mathrm{Li}_{20} \mathrm{Sn}_{80}$ $+1-5 \%$ RG-PuF , and 99-95\% $\mathrm{Li}_{20} \mathrm{Sn}_{80}+1-5 \% \mathrm{RG}-$ $\mathrm{PuO}_{2}$ fluids in liquid first wall, blanket and shield zones, ENDF/B-VII.0 evaluated nuclear data library from $10^{-11}$ to $20 \mathrm{MeV}$ and $9 \mathrm{Cr} 2 \mathrm{WVT}$ a structural material.

Fig. 1 shows variation of the neutron fluxes in the reactor system versus the mixture components of 9995\% $\mathrm{Li}_{20} \mathrm{Sn}_{80}+1-5 \% \mathrm{RG}-\mathrm{Pu}, 99-95 \% \mathrm{Li}_{20} \mathrm{Sn}_{80}+1-5 \%$ $\mathrm{RG}-\mathrm{PuF}_{4}$, and $99-95 \% \mathrm{Li}_{20} \mathrm{Sn}_{80}+1-5 \% \mathrm{RG}-\mathrm{PuO}_{2}$ in the liquid first wall, blanket and shield zones. In Fig. 1 was observed that the neutron flux increases with an increase in the heavy metals content in the system for selected the fluids. Fig. 1 shows the create a peak around $5 \%$ of $\mathrm{Pu}$, due to the fact that $\mathrm{Pu}$ has the highest plutonium density and fission reactions.

Fig. 2 shows the radial neutron flux distribution in the designed system for the various mixture compositions of molten salt and heavy metals. The variation of the neutron flux distribution in the inboard and outboard of the reactor system decreases nearly exponentially with distance from the reactor center (plasma) for selected the fluids.

Fig. 3 shows the average neutron flux distribution according to neutron energy spectrum $(0-20 \mathrm{MeV})$ in the reactor system for the selected fluids. In Fig. 3, it was seen that the average neutron flux distribution decreases between 0-14 MeV, a peak around $15 \mathrm{MeV}$ and decrease later in the designed system.

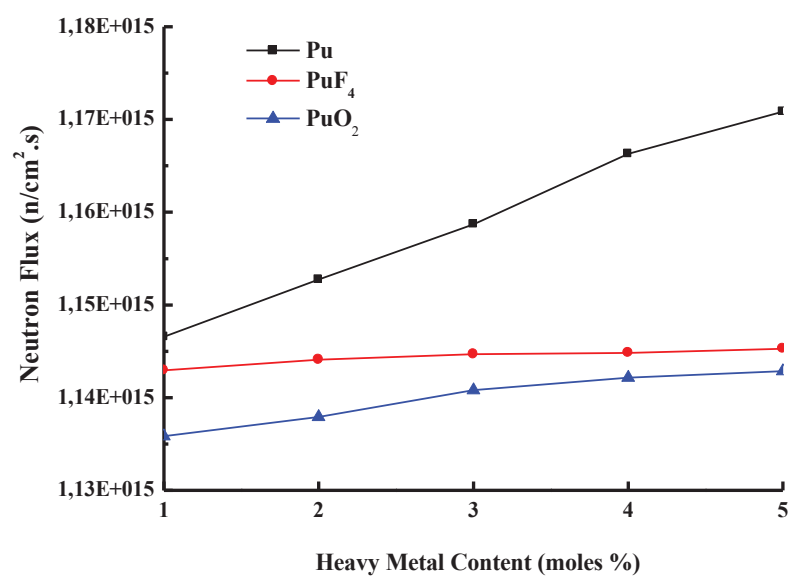

Fig. 1. The variation of the neutron fluxes in the reactor system versus the mixture components of molten salt and heavy metals.

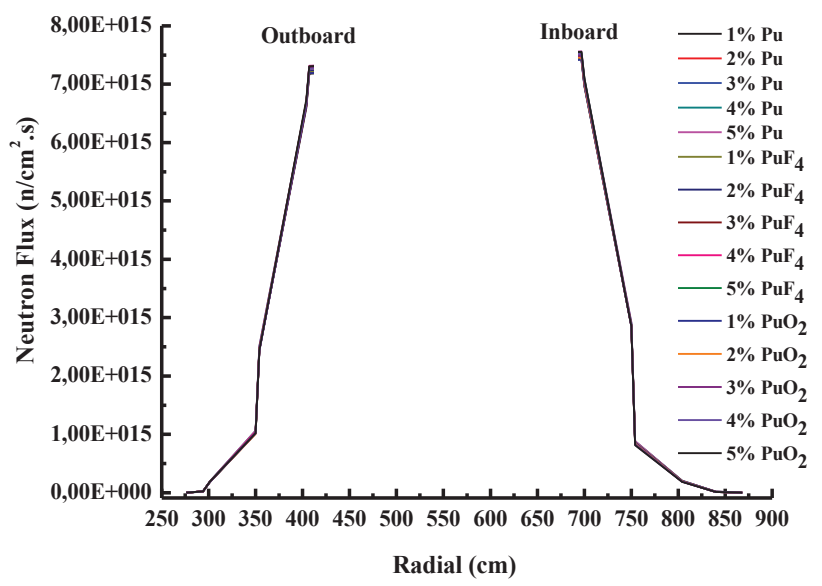

Fig. 2. The variation of the radial neutron flux distribution in the inboard and outboard of the reactor system for the selected fluids.

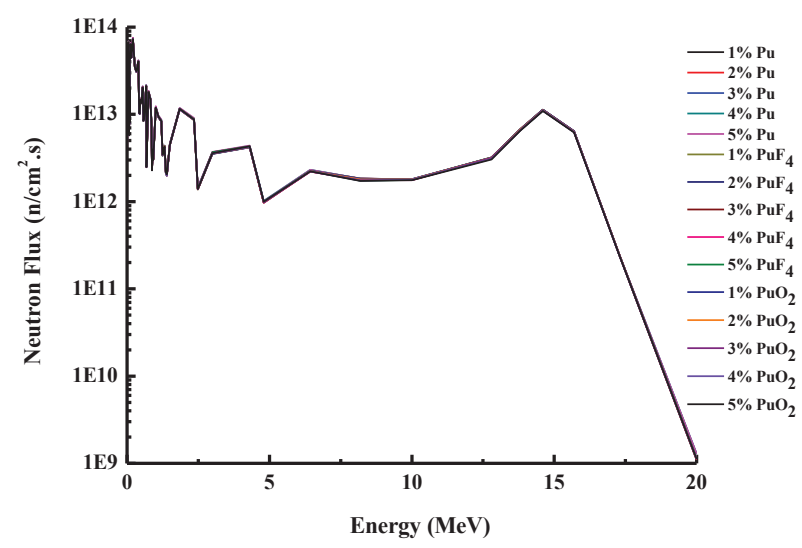

Fig. 3. The variation of the neutron flux distribution according to neutron energy spectrum in the reactor system for the selected fluids.

\section{Conclusions}

In this study were investigated the effect on the neutron flux distribution of selected fluids. The neutron flux 
increases with an increase in the heavy metals content for the selected fluids due to the fission reaction of plutonium isotopes, inelastic scattering of ${ }^{7} \mathrm{Li}$ and the exothermic ${ }^{6} \mathrm{Li}(\mathrm{n}, \alpha) \mathrm{T}$ reaction of ${ }^{6} \mathrm{Li}$ in the $\mathrm{Li}_{20} \mathrm{Sn}_{80}$ molten salt, $(\mathrm{n}, 2 \mathrm{n})$ reaction of beryllium, elastic and other nuclear reactions of atoms in the fuel zone. Therefore, in the calculation was observed that the radial neutron flux distribution decreases nearly exponentially with distance from the plasma for selected the fluids in the inboard and outboard of the reactor system. In this study, the average neutron flux distribution was investigated according to the neutron energy spectrum $(0-20 \mathrm{MeV})$ in the system for the selected fluids. The neutron spectrum produces high energy $\gamma$-rays in the range of $5-10 \mathrm{MeV}$ by $(\mathrm{n}, \gamma)$ reactions, $2 \mathrm{MeV}$ fission neutrons and $14.6 \mathrm{MeV}$ fusion neutrons. In the calculation was seen that the average neutron flux distribution due to fission, fusion and other nuclear reactions, and had a peak approximately 14-16 MeV, decreasing thereafter. The values between the $0-20 \mathrm{MeV}$ energy gap were approximately the same values of the neutron flux distribution according to the energy in the system for ratios and types different fifteen of fluids.

In conclusion, the neutronic calculations obtained in the liquid first wall, blanket and shield zones with 95\% $\quad \mathrm{Li}_{20} \mathrm{Sn}_{80}-5 \%$ RG-Pu fluid showed the best performance of the fifteen tested fluids.

\section{Acknowledgements}

This work was supported by İnönü University Research fund with the project number 2015/68.

\section{References}

1. S. Şahin, M. Übeyli, Energy Convers. Manage., 46, 3185 (2005)

2. H.M. Şahin, Ann. of Nucl. Energy, 34, 861 (2007)

3. B. Sarer, et al., Fusion Sci. Technol., 52, 107 (2007)

4. M. Günay, et al., Ann. of Nucl. Energy, 38(12), 2757 (2011)

5. M. Günay, et al., Ann. of Nucl. Energy, 55, 292 (2013)

6. IAEA, International Atomic Energy Agency, IAEA- TECDOC1349 (2003)

7. M. Piera, et al., Energy Convers. Manage., 51, 1758, (2010)

8. A. Ying, et al., APEX Interim Report, (1999)

9. B. Şarer, et al., Ann. of Nucl. Energy, 36, 417 (2009)

10. M. Günay, et al., Ann. of Nucl. Energy, 53, 59 (2013)

11. M.B. Chadwick, et al., Nucl. Data Sheets, 107, 2931, (2006)

12. D.B. Pelowitz, MCNPX User's Manual, Version 2.7.0, LA-CP11-00438 (2011)

13. J.J. Duderstadt, G.A. Moses, New York: John Wiley \& Sons, (1982) 